\title{
Blood Flow through Human Skeletal Muscle during and after Contraction
}

\author{
Michio Arai and Hiroyuki Endoh \\ Department of Orthopedic Surgery, Akita University School of \\ Medicine, Akita
}

ARar, M. and ENDoH, H. Blood Flow through Human Skeletal Muscle during and after Contracticn. Tchcku J. exp. Med., 1974, 114 (4), 379-384 - Muscle blood flow measurements were made with a heated thermocouple technique on the patients with ischemic museles and on control subjects during and after contraction. Simultancous reccrding of the muscle blood flow and electromyogram revealed that there is a direct correlation between the increase in the blood flow and the strength of muscular contraction. During strong sustained contraction, the initially increased blood flow fell toward the resting level followed by a reactive hyperemia, which was particularly marked in ischemic muscles. The findings suggested that the blood flow changes during contraction were related to mechanical processes, and that the post-contraction hyperemia was caused by the metabolic prcducts in the ischemic muscles. - muscle blood flow; heated thermocouple technique; muscular contraction; ischemia

Although it is well-known that muscular exercise causes an increase of blood flow in the active muscles, there is little information on the blood flow changes in the single skeletal muscle in man during and after contraction at different strengths. The reason is that the blood flow through a single muscle during exercise can never be measured directly by any methods such as plethysmography, electromagnetic flowmetry and tissue clearance method. In the present study, the heated thermocouple technique deseribed by Hensel and Ruef (1954) and Golenhofen et al. (1963) has been applied to the measurement of human muscle blood flow, and the report includes blood flow changes with different exercises in healthy subjects and in patients with ischemic disease of the extremities.

\section{Methods}

The muscle blood flow was measured by a flow meter, Shincorder (Model CTE-401, Shin-ei Co., Tokyo) and recorded with a graphic recorder (Rectinograph, Model 8S-12, San-ei Sokki Co., Tokyo).

The apparatus used for heating did not essentially differ from those used by Gibbs (1933), Grayson (1952) and Hensel and Ruef (1954).

The probe used consisted of a $12 \mathrm{~mm}$ long constantan wire, $0.05 \mathrm{~mm}$ in diameter, which was soldered at each end to copper wire, $0.05 \mathrm{~mm}$ in diameter; and a copper and constantan wire, $0.03 \mathrm{~mm}$ in diameter, for the heater. In the center of the needle type probe, a copper wire coated with polyurethane, $0.07 \mathrm{~mm}$ in diameter, was used for an electromyographic electrode which connected to an amplifier, and electromyogram and its

Received for publication, October 19, 1974. 


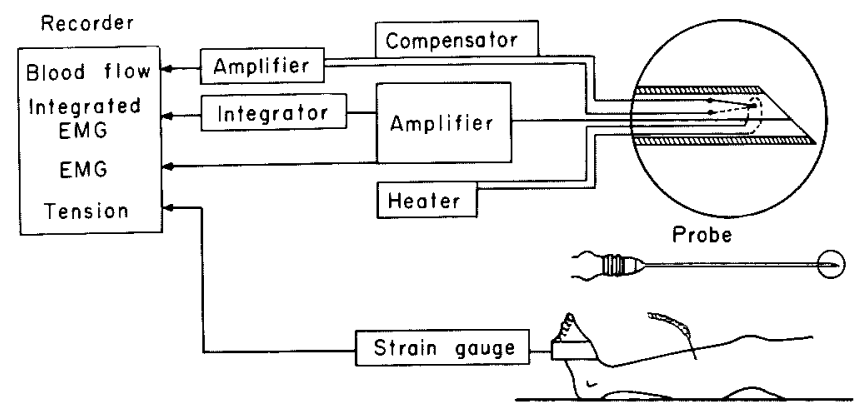

Fig. 1. Schematic diagrams of blood flowmeter and construction of needle type probe. Dotted line in the probe shows constantan wire.

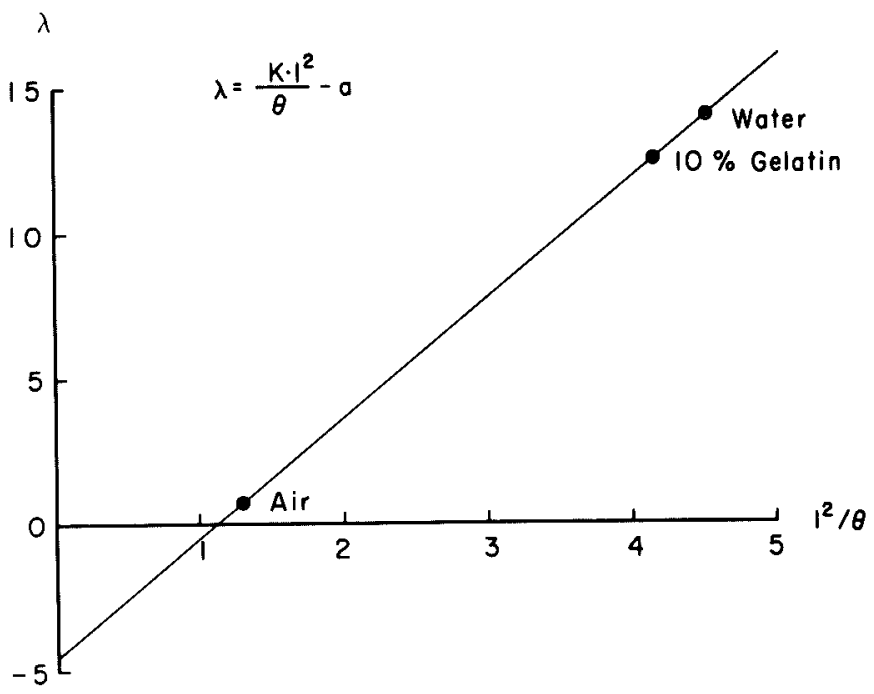

Fig. 2. The standardization of the probe. The relationship between $I^{2} / \theta$ and $\lambda$ was linear. The value of $k$ and $a$ was found to be 6.11 and $4.60 \times 10^{-4}$ respectively. $\lambda$, thermal conductivity $\left(\times 10^{-4} \mathrm{cal} / \mathrm{cm} \cdot \mathrm{sec} \cdot{ }^{\circ} \mathrm{C}\right) ; \theta$, temperature increment $\left({ }^{\circ} \mathrm{C}\right) ; I$, electric current (A).

integration curves were recorded on the same recorder. The construction of the probe and the circuits used are shown in Fig. 1. Muscle tension was also recorded using an electrical tensimeter with strain gauge (Type 1206 B, San-ei Sokki Co., Tokyo).

The measurements were carried out in a supine position after $20 \mathrm{~min}$ of bed rest. The needle was inserted through the skin into the muscle. About 5 min after the insertion, changes of muscle blood flow were recorded continuously.

Thermal conductivity was calculated as follows:

According to Golenhofen et al. (1963), thermal conductivity $(\lambda)$ is given by the formula

$$
\lambda=\frac{k \cdot I^{2}}{\theta}-\alpha
$$

where $\lambda$ is the thermal conductivity, $I$ is the heating current, $\theta$ is the temperature, $k$ and $a$ are constant.

The value of $k$ varies with the sensitivity of the probe and $a$ is caused by a heat 
transfer from heater to measuring point in the probe. The fact that $I^{2} / \theta$ is constant in different substances provides a method for the determination of $k$ and $a$. In a number of substances with known thermal conductivities, $I^{2} / \theta$ and $\lambda$ were plotted. The value of $\theta$ was calculated with the formula

$$
E=\delta \times \theta
$$

where $E$ was voltage $(\mu \mathrm{V})$ obtained from galvanometer and $\delta$ was voltage at increase of $1^{\circ} \mathrm{C}$, constant in the thermocouple. The substances used were air, water and $10 \%$ gelatin in water. Fig. 2 shows the relationship between $\lambda$ and $I^{2} / \theta$. Values of $k$ and $a$ were calculated with the following equations:

$$
\begin{gathered}
k=\frac{\theta_{1} \cdot \theta_{2}\left(\lambda_{1}-\lambda_{2}\right)}{I_{1}{ }^{2} \cdot \theta_{2}-I_{2}{ }^{2} \cdot \theta_{1}} \\
\alpha=\frac{k \cdot I^{2}}{\theta}-\lambda
\end{gathered}
$$

\section{RESULTS}

Fig. 3 shows the blood flow changes of the anterior tibial muscle in a healthy subject during and after contraction. Immediately after the beginning of the work the increase in muscle blood flow started. The rise in the blood flow remained constant in cases of moderate exercise in all healthy subjects. On the contrary, when the exercise was maximum a gradual fall of the blood flow always occurred, followed by a rapid increase in blood flow at the end of exercise, and this peak flow was followed by a gradual return toward the resting level.

The flow response varied significantly from subject to subject, and the increase seemed to be closely related to the degree of contraction. In Fig. 4 the maximum flow level, including peak flow, has been plotted against the strength of the muscle. It is noticed that there is a nearly linear relationship between them.

Fig. 3 also shows the recordings of muscle blood flow during sustained contrac-
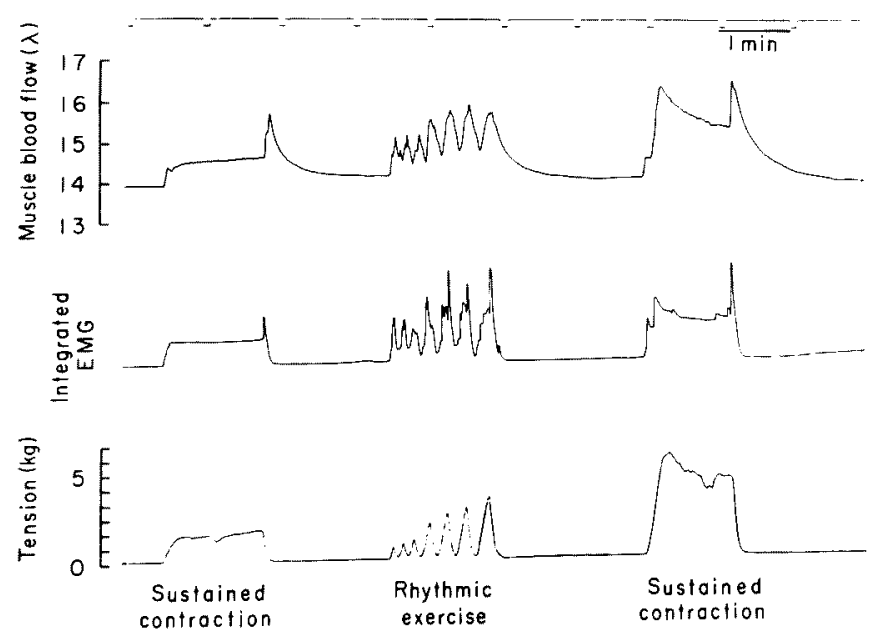

Fig. 3. Blood flow changes in the anterior tibial muscle during sustained contraction and rhythmic exercise in a healthy subject. 


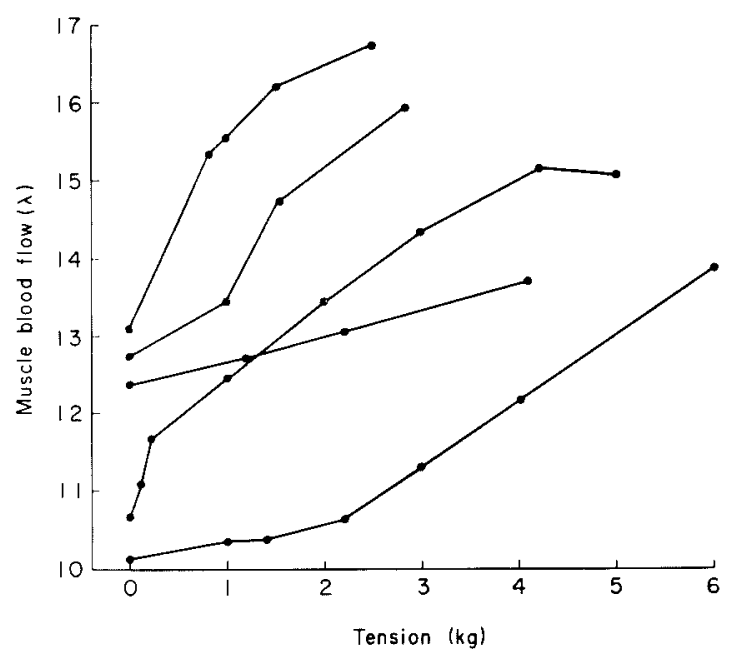

Fig. 4. Relation between blood flow increase and tension of the anterior tibial muscle in five healthy subjects.
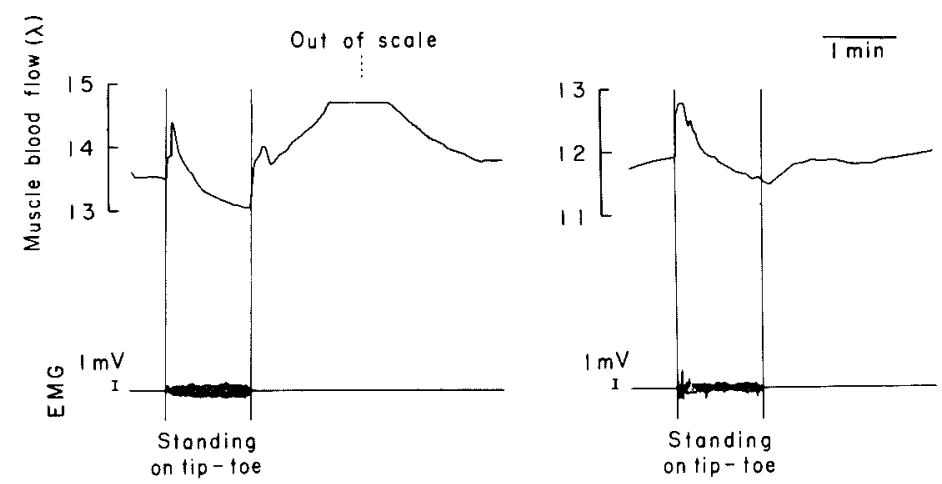

Fig. 5. Changes of blood flow of the calf muscle in limb of femoropopliteal artery occlusion (left side) and in normal limb (right side).

tion and during rhythmic exercise. During rhythmic exercise, alternate contractions and relaxations at the rate of one per second, fluctation of muscle blood flow was observed. Although the slope of the increase was essentially the same as in sustained contraction, there was no decrease of blood flow below that of the resting level but little postexercise hyperemia.

In the patients with ischemic disease of the extremities, the increase of muscle blood flow during exercise was significantly lower than in control subjects and the postcontraction hyperemia was higher than the flow during contraction. In a patient with a femoropopliteal artery occlusion, a marked decrease in the flow occurred during standing on one tiptoe and postcontraction hyperemia was prominent (Fig. 5). There was still a further increase in blood flow through the calf muscle and the highest values were attained several minutes after exercise. 


\section{Discussion}

It has been generally assumed that the results obtained with the heated thermocouple technique cannot be compared with the other values since this instrument gives essentially semi-quantitative recording. Gibbs (1933) and Bill (1962) emphasized that the method could only be used for determinations of qualitative changes in blood flow if the probe was not standardized in each experiment. With Hensel's method for the standardization, however, it is possible to calculate the thermal conductivity $(\lambda)$ of human skeletal muscle, and this allows comparison between the two values of blood flow in the extremities using two instruments of an equal sensitivity.

The present results are in agreement with observations of many previous workers (Anrep and v. Saalfeld 1935; Kjellmer 1964; Hlavová et al. 1965; Schroeder 1965) that there is a sharp increase in muscle blood flow at the beginning of a period of exercise. With simultaneous recording of electromyogram, it was possible to measure the time relationship between the start of muscle contraction and the beginning of increase in muscle blood flow with high speed recording. In the present study, an average period of 0.17 sec was read on the recorder. It should be pointed out, however, that there was a lag, 0.1 to $0.2 \mathrm{sec}$, due to sensitivity of the apparatus in the recording of flow changes. Therefore, the correlation is so close that the increase of muscle blood flow seems to be caused by the mechanical effect of muscle contraction directly.

In light exercise this increase lasts throughout the period of contraction. As shown in Fig. 4, the increase in muscle blood flow is closely related to the amount of exercise. Khayutin (1968) suggested that the transmission of signals from the muscle fiber to its blood vessels may not be chemical but a mechanical process and concluded that the starting of hyperemia may be caused by a decrease in longitudinal tension in arteriolar walls in most distal arterioles in contact with sarcolemma. Our finding on the direct relationship between the increase in muscle blood flow during contraction and action potentials simultaneously recorded is also in agreement with the mechanical theory.

After a few seconds of exercise, the muscle blood flow often fell toward the resting level, and after exercise stopped, it rose again to higher levels. The initial loss of flow was greater during heavy exercise than during light exercise. This shows that marked retention of blood occurred in the muscle during strong contraction, causing a considerable rise in intramuscular pressure. The peak flow must then be taken as a sign of vasodilatation during the contraction as reported by Hillestad (1963). Previous workers (Barcroft and Millen 1939; Koppelmann 1968; Mortimer et al. 1971) have also shown that the strong sustained contraction of human muscle mechanically decreases the blood flow.

In some cases of ischemic disease, the muscle blood flow during exercise may bo lower than the resting flow, and it would seem that the main effect of the increase in intramuscular pressure was to cause a reduction in flow. In the patients with ischemic muscles, the reduction of blood flow during sustained contrac- 
tion was followed by a marked postcontraction hyperemia and the hyperemia curve becomes prolonged in a protracted shape. These findings are similar to the observations of Hillestad (1963) and of Koppelmann (1968). The reactive hyperemia may be related with the ischemic muscles where unkown metabolites are washed out more slowly than normal. Thus a chemical factor seems to be a possible cause of the postcontraction hyperemia.

\section{References}

1) Anrep, G.V. \& v. Saalfeld, E. (1935) The blood flow through the skeletal muscle in relation to its contraction. $J$. Physiol. (Lond.), 85, 375-399.

2) Barcroft, H. \& Millen, J.L.E. (1939) The blood flow through muscle during sustained contraction. J. Physiol. (Lond.), 97, 17-31.

3) Bill, A. (1962) Studies of the heated thermocouple principle for determinations of blood flow in tissues. Acta physiol. scand., 55, 111-126.

4) Gibbs, F.A. (1933) A thermoelectric blood flow recorder in the form of a needle. Proc. Soc. exp. Biol. Med. (N.Y.), 31, 141-146.

5) Golenhofen, K., Hensel, H. \& Hildebrandt, G. (1963) Durchblutungsmessung mit Wärmeleitelementen, Georg Thieme Verlag, Stuttgart.

6) Grayson, J. (1952) Internal calorimetry in the determination of thermal conductivity and blood flow. J. Physiol. (Lond.), 118, 54-72.

7) Hensel, H. \& Ruef, J. (1954) Fortlaufende Registrierung der Muskeldurchblutung am Menschen mit einer Calorimetersonde. Pflügers Arch. ges. Physiol., 259, 267280.

8) Hillestad, L.K. (1963) The peripheral blood flow in intermittent clandication. VI. Plethysmographic studies. The blood flow response to exercise with arrested and with free circulation. Acta med. scand., 174, 671-685.

9) Hlavová, A., Linhart, J., Přerovský, I., Ganz, V. \& Fronék, A. (1965) Leg blood flow at rest, during and after exercise in normal subjects and in patients with femoral artery occlusion. Clin. Sci., 29, 555-564.

10) Khayutin, V.M. (1968) Determinants of working hyperaemia in skeletal muscle. In: Circulation in Skeletal Muscle, edited by O. Hudlická, Pergamon Press, p. 145.

11) Kjellmer, I. (1964) The effect of exercise on the vascular bed of skeletal muscle. Acta physiol. scand., 62, 18-30.

12) Koppelmann, J. (1968) Das Verhalten von Haut- und Muskeldurchblutung bei chronisch arteriellen Verschlusskrankheiten mit Claudicatio intermittens unter besonderer Berücksichtigung der aktiven U̇bungsbehandlung. Ergebn. Chir. Orthop., 51, $9-27$.

13) Mortimer, J.T., Kerstein, M.D., Magnusson, R. \& Petersén, I. (1971) Muscle blood flow in the human biceps as a function of developed muscle force. Arch. Surg., 103, 376-377.

14) Schrocder, W. (1965) Was wissen wir über die vegetative Steuerung der Skelettmuskeldurchblutung? Acta neuroveget., 28, 75-94. 